\title{
The Acute Effects of Different Warm-up Protocols on Change of Direction and Reactive Speed Performance
}

\author{
Büşra Adıgüzel ${ }^{1}$, Ertuğrul Gelen ${ }^{1}$, Dilşad Mirzeoğlu ${ }^{1}$, Suat Yıldız ${ }^{2}$, Volkan Sert $^{3}$ \\ ${ }^{1}$ Sakarya Üniversitesi, Faculty of Sport Sciences, Turkey \\ ${ }^{2}$ Manisa Celal Bayar Üniversitesi, Faculty of Sport Sciences, Turkey \\ ${ }^{3}$ Van Yüzüncü Y1l Üniversitesi, School of Physical Education and Sport, Turkey \\ Correspondence: Suat Yıldız, Manisa Celal Bayar Üniversitesi, Faculty of Sport Sciences, Turkey.
}

Received: April 9, 2018

Accepted: May 8, $2018 \quad$ Online Published: May 15, 2018

doi:10.11114/jets.v6i7.3176

URL: https://doi.org/10.11114/jets.v6i7.3176

\begin{abstract}
The purpose of the study was to examine the acute effects of open and closed skill warmings on change of direction and reactive speed performance.

113 high school students participated in the study voluntarily. The students were divided into three groups as general warming (GW), open skill warming (OSW) and closed skill warming (CSW). Reactive speed and change of direction test was performed after the general warming (GW), open skill warming (OSW), and closed skill warming (CSW) protocols were applied in our study. In this study, general warming protocol was designed as control application and other warming protocols were designed as experimental application.

In terms of the change of direction performance, with general warming the difference between OSW ( $p>0.01)$ and CSW ( $p>0.01$ ) was found significant. However, the difference between closed skill warming and open skill warming was not significant. The difference between general warming and open skill warming $(\mathrm{p}<0.01$ ) was found to be significant in terms of the reactive speed. However, the difference between closed skill warming (p>0,097) and open skill warming ( $p>0.0212)$ was not significant.

In our study, in which we examined the acute effects of on and off skill warmings on different speeds and reactive speeds of different warm-up protocols, it is thought that if warming includes open and closed skills, both change of direction performance and reactive speed performance can be increased.
\end{abstract}

Keywords: open skill warm-up, closed skill warm-up, change of direction, reactive speed

\section{Introduction}

Flexibility exercises performed before the athletic training or competitions are one of the most important factors of mental and physiological preparation. Physiologically, warming has been shown to increase neurological function in the form of muscle heat and muscle blood flow, coordination and proprioceptive susceptibility (Cilli, Gelen, Yildiz, Saglam, \& Camur, 2014; E. Gelen, 2010; E. Gelen, Dede, Bingul, Bulgan, \& Aydin, 2012; Ertuğrul Gelen, 2011).

Muscle elasticity and joint mobility acquired by warming reduces the risk of injury and allows the organism to prepare for loading (Yıldız, Çilli, Gelen, \& Güzel, 2013). These features affect the ability of decision and the reaction speed of the athlete (Kramer, Huijgen, Elferink-Gemser, \& Visscher, 2017; Munivrana, Filipčić, \& Filipčić, 2015; Roetert, Piorkowski, Woods, \& Brown, 1995; Sheppard, Young, Doyle, Sheppard, \& Newton, 2006). The athlete should move according to the action that the opponent will take and the opponent's strokes, decision that is given and the planned progress. The given action decisions to win and get success should be effective, quick and quality. The abrupt start, speed, slowdown, halt and change of direction make possible the athlete to get the right position and also the effective and quality strokes in the right position may provide the athlete success (Yıldız, Pınar, \& Gelen, 2017). Sometimes, the quality of the athlete's abrupt change of direction feature cannot be enough. If the athlete doesn't know the direction to take, he or she needs reactive speed to use this feature in a good way (Gabbett, Sheppard, Pritchard-Peschek, Leveritt, \& Aldred, 2008).

When the athlete includes the open and closed skills in the warming protocols, may this affect the stated feature? Based 
on this question, the aim of the study is defined as the analysing the acute effects on the change of direction and reactive speed of the open and closed warming which are the different warming items.

\section{The Method}

The students participated in the study are divided into three homogeneous groups as GW, OSW and CSW. Each group performs the change of direction and reactive speed test after performing all warming protocol.

\subsection{The Participants}

The demographic features of the participants in our study are stated in Table 1.

113 students from Sakarya Serdivan Anatolian High School participated in the study voluntarily. All students joined the $\mathrm{PE}$ and sport lessons two hours in a week. We wanted that the students didn't exercise hardly within 24 hours before the applications and tests and eat at least two hours before. All students were informed about the risks and the benefits of their participating in this study and they signed the disclosure permission form before being applied any test.

However, we moved along with the "Helsinki Declaration" in the each process of the study.

Table 1. The Demographic features of the athlete

\begin{tabular}{lllll}
\hline & Arithmetic average & Standard deviation & Min. & Max. \\
\cline { 2 - 3 }$(\mathbf{G W})$ & & & & \\
Age $($ year $)$ & 16,8 & 0,53 & 16 & 18 \\
Height $(\mathrm{cm})$ & 173,0 & 9,87 & 150 & 190 \\
Weight $(\mathrm{kg})$ & 65,84 & 14,10 & 40 & 95 \\
\hline Open Skill Warming $(\mathbf{O S W})$ & & & & \\
Age $($ year) & 17,03 & 0,71 & 16 & 18 \\
Height $(\mathrm{cm})$ & 177,5 & 7,54 & 160 & 191 \\
Weight $(\mathrm{kg})$ & 72,0 & 10,5 & 41 & 89 \\
\hline Close Skill Warming $(\mathbf{C S W})$ & & & & \\
Age $($ year $)$ & 16,9 & 0,59 & 16 & 18 \\
Height $(\mathrm{cm})$ & 173,8 & 9,95 & 153 & 192 \\
Weight $(\mathrm{kg})$ & 69,3 & 6,61 & 40 & 95 \\
\hline
\end{tabular}

\subsection{The Protocols}

The general warming protocol

It consisted of 5 minutes low- density running. During 5 minutes, we got students to run with the density that their heart rate reached 120 per minute. By making the defined randomly three students of each 10 people - groups wear the heart rate monitor (810i Polar Electro Inc., Finland), we observe the density of warming and also clear away the difference between the students. After 5 minutes warming run, there was not any applied stretching or dynamic exercise.

The open skill protocols

The participants are divided equally into 2 groups with six students. We got the two teams to play handball in the defined field. When the same team player made ten passes to each other, they got one point and when the opponent team got the ball from them at the same time, we reset the score and the opponent got the right of the pass. This game continued 5 minute. After the time was over, the participants made reactive speed and change of direction test without stretching.

\section{Closed skill warming protocol}

The participants as groups were performed the closed skill warming protocols. The warming protocols: Skipping, slapping hands on hips, cut- off, forward lunch stepping, zigzag run (increasingly) were performed by being accompanied with the trainer. The protocols kept on 5 minutes along. After the time was over, the participants made reactive speed and change of direction test without stretching.

\section{The Methods of Measurement}

\subsection{Reactive Speed Test}

Reactive speed test was performed in the test protocol in the figure 1 that was organized in the school garden. We placed a black mat within 1 meter distance from the starting line as in the figure and four tennis ball 5 meters far from the mat. However, the monitor was positioned to show the direction to go randomly.

When the participants were on the starting line by jumping slightly and stepping with two feet, we started the time and the random direction was appeared on the screen. The participants run towards the tennis ball in that shown direction, shot it and got back the mat. When the participants stepped the mat two times, any other direction was appeared and 
they got back by running toward the ball in that direction and shot it with hand. This process was performed four times without stopping. When the participant stepped on the mat that was in the starting line by return the fourth time, the participant stopped time and finished the test. Each participant performed this test two times and the best scores were recorded. There were 5 minutes breaks between the trials.

\subsection{The Change of Direction Speed Test}

The change of direction test was performed on the test battery on which the reactive speed test was applied (Figure1). While the athletes were in the starting line, it was told them to shot the tennis ball in the sort order defined before (A-B-C-D) and get back. The test content: when the athlete stepped on the mat in front of the starting line, we started time and got back after shooting the ball with hand in the direction of $\mathrm{A}$. The athlete run the ball in the direction of $\mathrm{B}$ and shot the ball and got back the mat. This process kept on also for $\mathrm{C}$ and $\mathrm{D}$ directions without stopping and when the athlete stepped on the mat in the starting line after shooting the ball, photocell stopped the time. Each participant performed this test two times and the best scores as time were recorded. There were 5 minutes breaks between the trials.

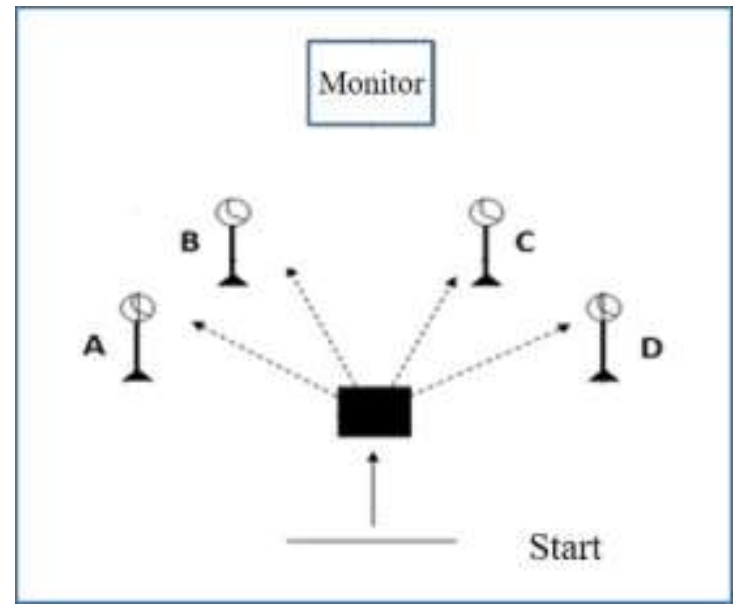

Figure 1. Reactive Speed and change of direction test battery

\subsection{The Statistical Analysis}

The statistics of all variables' definers were calculated. In this study, GW protocol was designed as the control application and the other warming protocols (OSW and CSW) were designed as the experiment application. The variance analysis test (ANOVA) was applied to find the difference between the warming protocols, however, Tukey test was applied to find which warming protocols made this difference. The significance level was defined as $(\mathrm{p}<0.05)$.

\section{The Results}

The speed points of the direction change after the different warming protocols are shown in Graphic 1 . In terms of the direction change, the difference between GW and OSW ( $\mathrm{p}<0.01$ ) and between GW and CW (p<0.01) was found significant. However, the difference between CSW and OSW wasn't observed as significant ( $\mathrm{p}<0.05$ ). According to the results, the change of direction speed performance increases following the open and closed skill training that are performed after running in the low density aerobic quality.

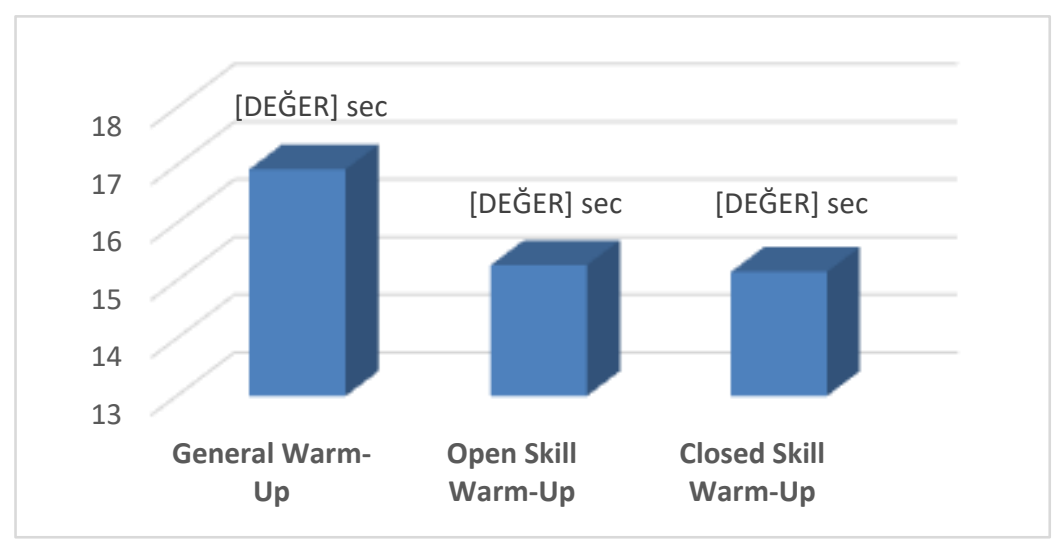

Graphic1. The speed rates of the direction change 
Reactive speed points after different warming protocols are shown in Graphic 2. In terms of reactive speed, the difference between GW and OSW ( $\mathrm{p}<0.01$ ) was found significant, however, the difference between CSW and OSW wasn't found significant ( $\mathrm{p}<0.05$ ), beside that the difference between CSW and OSW, as well. ( $\mathrm{p}<0.05$ ). According to the results, reactive speed performance increased following the closed skill training that were performed after running in the low density aerobic quality.

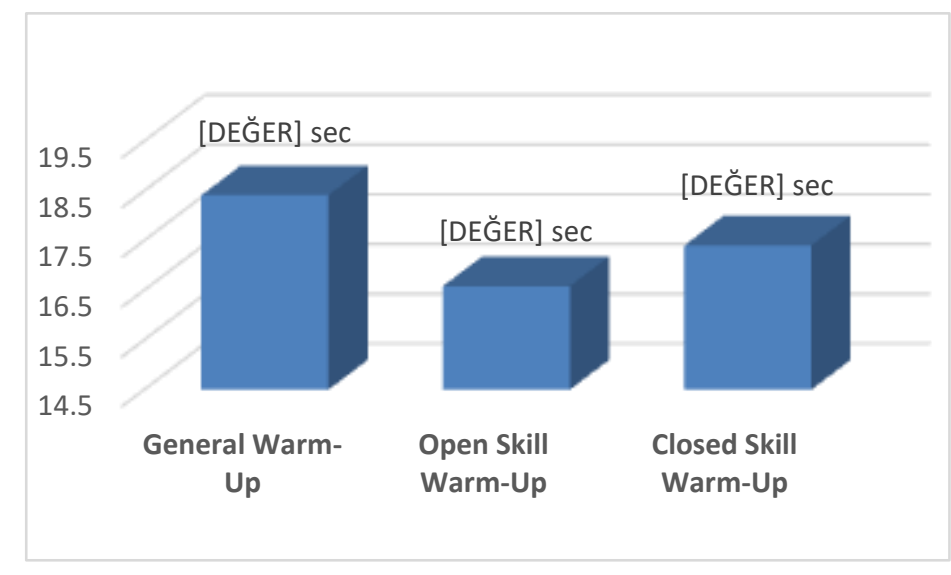

Graphic 2. Reactive speed rates

\section{The Discussion and the Results}

In our study that we search the acute effects of open and closed skill warming of different warming protocols on the change of direction and reactive speed, it is believed that the warming may increase both the change of direction and reactive speed, in the case that the warming involves in the open and closed skills. In the study of Gabbett and his friends (Gabbett et al., 2008), there wasn't found any significant difference between open and closed skill warming protocols, but they couldn't show the effects of the warming protocols as they didn't use any control application. In our study, the significant difference between the control application and open skill warming protocol was observed, however, we couldn't find any significant difference between control application and closed skill warming protocol. While there wasn't any difference between open and closed skill statistically, it was observed that and the direction change and reactive speed performance values of the participants warming were observed better with the open skill warming protocol.

The background of the participant in the study can define the direction change and reactive speed performance. While the fact that the participant is athletic increases the foresight, better results can be observed. In case that the participant is not athletic, the performance values can be lower as the foresight is weak. The studies on this are stated in the compilations edited by Sheppard and Young.( Sheppard\&Young,2006)

The participants that participated in our study voluntarily includes the high school student that don't have any athletic background. However, the significant differences are observed according to the control application between open and closed skill warmings. The open skill warming protocol gets better results with the performance of the direction change and reactive speed. Regardless of the participant's athlete background, to perform dynamic warming with open skill increases the performance in the activities that need reactive speed and front change.

\section{References}

Cilli, M., Gelen, E., Yildiz, S., Saglam, T., \& Camur, M. (2014). Acute effects of a resisted dynamic warm-up protocol on jumping performance. Biol Sport, 31(4), 277-282. https://doi.org/10.5604/20831862.1120935

Gabbett, T. J., Sheppard, J. M., Pritchard-Peschek, K. R., Leveritt, M. D., \& Aldred, M. J. (2008). Influence of closed skill and open skill warm-ups on the performance of speed, change of direction speed, vertical jump, and reactive agility in team sport athletes. J. Strength Cond. Res., 22(5), 1413-1415. https://doi.org/10.1519/JSC.0b013e3181739ecd

Gelen, E. (2010). Acute effects of different warm-up methods on sprint, slalom dribbling, and penalty kick performance in soccer players. J Strength Cond Res, 24(4), 950-956. https://doi.org/10.1519/JSC.0b013e3181cb703f

Gelen, E., Dede, M., Bingul, B. M., Bulgan, C., \& Aydin, M. (2012). Acute effects of static stretching, dynamic exercises, and high volume upper extremity plyometric activity on tennis serve performance. J. Sports Sci. Med., $11(4), 600-605$. 
Gelen, E. (2011). Acute effects of different warm-up methods on jump performance in children. Biology of Sport, 28(2), 133-138.

Kramer, T., Huijgen, B. C., Elferink-Gemser, M. T., \& Visscher, C. (2017). Prediction of Tennis Performance in Junior Elite Tennis Players. J. Sports Sci. Med., 16(1), 14-21.

Munivrana, G., Filipčić, A., \& Filipčić, T. (2015). Relationship of Speed, Agility, Neuromuscular Power, and Selected Anthropometrical Variables and Performance Results of Male and Female Junior Tennis Players. Coll. Antropol., 39 Suppl 1, 109-116.

Roetert, E. P., Piorkowski, P. A., Woods, R. B., \& Brown, S. W. (1995). Establishing percentiles for junior tennis players based on physical fitness testing results. Clin Sports Med, 14(1), 1-21.

Sheppard, J. M., \& Young, W. B. (2006). Agility literature review: classifications, training and testing. J. Sports Sci., 24(9), 919-932. https://doi.org/10.1080/02640410500457109

Sheppard, J. M., Young, W. B., Doyle, T. L., Sheppard, T. A., \& Newton, R. U. (2006). An evaluation of a new test of reactive agility and its relationship to sprint speed and change of direction speed. J. Sci. Med. Sport, 9(4), 342-349. https://doi.org/10.1016/j.jsams.2006.05.019

Yıldız, S., Pınar, S., \& Gelen, E. (2017). Çocuk Tenisçilerde Fonksiyonel Antrenman (Suat. Yıldız Ed.). Germany: Lambert Academic Publishing.

Yıldız, S., Çilli, M., Gelen, E., \& Güzel, E. (2013). Acute effects of differing duration of static stretching on speed performance. International Journal of Human Sciences, 10(1), 1202-1213.

\section{Copyrights}

Copyright for this article is retained by the author(s), with first publication rights granted to the journal.

This is an open-access article distributed under the terms and conditions of the Creative Commons Attribution license which permits unrestricted use, distribution, and reproduction in any medium, provided the original work is properly cited. 